\title{
Understanding and Developing Computational Thinking
}

\author{
Ronghua Lu \\ Jingdezhen Ceramic Institute, Jingdezhen, 333403, China \\ Irhlucy2003@163.com
}

Keywords: Scientific Thinking, Computational Thinking, Education, Computing, Thinking training

\begin{abstract}
How to cultivate students' computational thinking is an important task for the current research of computer education. This thesis expounds the concept and connotation of computational thinking, and explains its enlightenment for computer science research and computer education.
\end{abstract}

\section{What is computational thinking}

Thinking is a way and method for human being to learn the world. Way of thinking is an important content for human to do epistemology research. Countless philosophers, thinkers and scientists have done distinctive thinking researches on human's thinking method, and have had much profound insights. At present, there are three accepted natural scientific methods in the field of science: theoretical method, experimental method and computing method. Correspondently, there are three major scientific thoughts: theoretical thinking, experimental thinking and computing thinking. Computational thinking can be dated back to the ancient mathematics: the ancient Chinese scholars believe that when a problem can be solved by an abacus, it is solvable, and this is called "algorithm" thought. From the abacus to the calculator, electronic computer, the Internet and the cloud computing, the content of the computational thinking keeps expanding; from elementary school, middle school to university and the graduate student education, the computational thinking was used faintly. It was until 2006, people began to pay attention to computational thinking, when Professor Jeannette M. Wing at Carnegie Mellon University in the United States defined it clearly and systematically.

In a narrow sense, computational thinking is the thinking process of data driven; in a broad sense, computational thinking is a thinking process with quantitative manner based on calculation method. Scholars generally agree with Professor Jeannette M. Wing's definition "computational thinking is a series of thinking movement using the basic concepts of computer science to solve problem, to design system, and to understand human behavior which covers computer science. It is thus clear that, computational thinking is a kind of nature way of thinking which everybody shall possess, like reading, writing and arithmetic. It shall one of the most basic, the most common, the most suitable and indispensable basic way of thinking: when you go to school in the morning, you put the things in demand in your backpack, that is called "preset and cache"; When someone lost his articles, you suggest he to walk along his path to look for them, this is called "pushback"; when you make a decision to rent or buy a house for yourself, that is called "online algorithm"; when you consider which line to stand in to pay the bill in the supermarket, that is called "multiple-server system" performance model; why your phone can also be used in the case of power failure, that is called "failure independence and redundancy design".

Computational thinking and computational thinking ability are two different concepts. The former 
one is a kind of thinking method, the latter one refers to the ability to apply computational thinking.In fact, we are not to cultivate the computing thinking (method), but to guide people to learn and master it. Thus, it can be used effectively for problem solving, and people can master this kind of skill. If a person does not possess a calculation thinking ability, he will be in the dry tree in a competition; if the learners don't get educated for the computational thinking ability, it will be impossible for their country to win the fierce competition in the international environment. Not only the computer professionals, but also all the common educatee shall possess the computational thinking ability.

\section{How to calculate the computational thinking ability in computer education}

In the field of computer science, computational thinking is a reflection of the comprehensive ability to solve problem, to design system, and to understand human behavior. To develop students' computing thinking is to think about information problems "like computer scientists". Although computational thinking has many characteristics of the computer science, yet it is not exclusive of computer science. Even without computer, computational thinking is also developing gradually, and some contents have nothing to do with computer. But the advent of the computer has brought the fundamental change to the research and development to the computational thinking.

Computer course is not the only curriculum to develop computational thinking, but it is the best one. Due to the fast processing of information and symbol, it is possible for computer to actually realize some processes which can only be achieved theoretically before. It is a goal and challenge for computer education to turn the characteristics and methods of computational thinking into the basic content and to develop students' computing thinking ability. In terms of computer course teaching, inchoate teaching is mainly to develop skills, and to develop into application ability. In recent years, on the basis of ability training, thinking cultivation was put forward. This shows that, unprecedented importance was attached to students' scientific thinking in the computer curriculum.

It is a new advance and challenge to cultivate computational ability to actually form the ability of computational thinking. Computer curriculum is a science strongly requires both theory and practicality, thus students must experience theoretical study and practical operation in order to realize the whole process of training from idea to product. Computer curriculum can do relative training on the contents, but the thinking training shall be implemented from the education system comprehensively. For the masses of users, symbol, program, algorithm are the basis of computer technology, and the foundation of understanding and realizing computer problem solving; due to the different systematic levels of abstraction and virtuality, and the growing technology, it requires people to learn new contents; The basic methods in computing course can only be mastered, understood and knew in the computing thinking ability training, because it is not so easy to master comprehensively. according to the teaching objectives and teaching content knowledge, It is necessary to select some " universal " content, to find an entry point to draw forth the issues to arouses student's study enthusiasm, stimulate their learning motivation: That means, teachers shall do further study on the teaching material and curriculum, and put forward some problems representativeness and applicability, to cover the whole teaching content of knowledge and thinking method; students shall know their learning objectives, understand their problems to be solved, and get into the learning situation. No matter what part of the people, their thinking ability cultivation shall all start from establishing the corresponding consciousness:

(1) To establish the basic awareness of "computing": to believe that computing technology can 
enhance our "ability"; there are unique advantages when use mechanical approach for problem solving (abstract description and thinking can be executed mechanically).

(2) To understand the basic functions of "computing" : software system, hardware system, application system provided different means for people's production and living, we know whether they are good at something or not, and we know what advantage and disadvantage do they have.

(3) To master the basic methods of "computing" : in the development of computing course, there are a lot of effective problem solving methods, such as recursive, reuse, parallel, modularization and incremental refinement, etc. They are not only effective in computing subject, but also be effectively applied in other disciplines.

(4) To use the basic tools of "computing": to solve the problems in the computing course, we can use software tools, hardware tools, system and all kinds of languages (assembly, high-level language, command). When we realize programs in different carriers, through abstract representations, selection and design effective algorithm and ideology, it can be solved even better.

(5) To possess the basic ability of "computational": to combine multiple channels and approaches to solve problems efficiently, such as: professional knowledge, consciousness, thought, method, technology, tool, environment, resources and so on.

\section{Conclusion}

From ancient times to the present world, all the education is for the sake of people's development. The key of man's development lies in their mind. Computational thinking is now closely related to our work and life, so it should be an integral part of human viability. The formation of one's scientific thinking ability, must be in accompany with improved innovation ability; the popularization of the social science of thinking ability must follow the revitalization and the prosperity of a nation. When computing thinking be integrated into the human activities, it shall be should grasped and used as an effective tool by everyone everywhere for problem solving. Naturally, it shall be effectively integrated into our each lesson. Merely, the thinking ability cultivation in computer course is a relatively long process, it requires our continuous explore and practice.

\section{Acknowledgements}

This research was support by the grants from project of Jingdezhen Ceramic Institute - Ability training and research on computing thinking of Engineering master, and Jiangxi province education department project (NO.JXJG-13-11-7, NO.JXJG-13-11-18), and The national institutions of higher learning computer education research project (ER2013025 and ER2014019).

\section{References}

[1] Seymour Papert. An Exploration in the Space of Mathematics Educations[J]. International Journal of Computers for Mathematical Learning, Vol.1,1996: 95-123.

[2] Jeannette M. Wing. Computational Thinking[J]. Communications of the ACM, Vol.49, No.3,2006: 33-35.

[3] Guo-liang Chen, Zhi-qiang Wang, Rui Mao. An introduction to computational thinking[M]. Beijing:Higher Education Press, 2012.

[4] Xu-hong Qian. Change your thinking[M]. Shanghai:Shanghai wenyi press,2012. 
[5] Rong-sheng Dong. Introduction to Computer Science-- Idea and Method[M]. Beijing:Higher Education Press,2007.

[6] Lian Li. Computational Thinking - Concepts and Challenges[J]. China University Teaching, Vol.1,2012:7-12.

[7] Guo-liang Chen, Rong-sheng Dong. The Expression System of Computational Thinking[J]. China University Teaching, Vol.12,2013:22-26.

[8 Zong-li Jiang. I have seen of Computational Thinking[J]. China University Teaching, Vol.9,2013:5-10.

[9] Xiao-ming Li. The understanding of the interdisciplinary computational thinking teaching and the practice[J]. China University Teaching, Vol.11,2012:4-5.

[10]Hua-min Ren, Ming Chen. Research on Cultivating Applied Talents with Computational Thinking[J]. Computer Education, No.5,2010:61-63.

[11] Ya-zong Zhu, Computational Thinking: its Scientific Position, Basic Principles and Innovation Me thods[J]. Computer Science, Vol.36 No.4 ,2009:53-55,93.

[12]Wen-chong Shi. My Views of Computational Thinking[J]. Computer Science, Vol.41 No.2,2014:11-14.

[13]Rong-hua Lu,Bing-xiang Liu,Yong-kang Peng. Computational Thinking training in computer foundation teaching of applied undergraduate colleges and universities[J]. China Computer \& Communication, Vol.9,2013:203-204.

[14] Bing-xiang Liu, Jun-yao Ye, Rong-hua Lu, Yong-kang Peng. Research and Practice of Ability Training of Computational Thinking in the Teaching of College Computer Course[J]. Modern Comupter, Vol.12,2013:36-39.

[15] The ministry of education of institutions of higher learning of university computer teaching steering committee. Declaration of computational thinking teaching reform [J]. China University Teaching, Vol.7,2013.

[16] Wen-hu $\mathrm{Wu}$, Jian-de Wang. Is commonly used in the program design calculation way of thinking --the collegiate programming contest advanced tutorial[M]. Beijing: China Railway Press,2009:180-184. 